\title{
Editorial
}

\section{Las fuerzas sociales y el debate nacional}

Con toda la complejidad que representa el espectro de fuerzas sociales en el pais es posible dilerenciarlas atendiendo a criterios tales como la manera de entrentar los problemas económico-sociales, asi por ejemplo tendríamos un primer agrupamiento en torno a quienes sostienen que el sistema posee en sl mismo la capacidad de efectuar sus propias correcciones sin necesidad de que intervenga el Estado, basta con dejar que actúen libremente las fuerzas del mercado; una segunda posición estaría representada por quienes confían en el sistema pero con una participación activa del Estado en la economía, esto es, no dejar en plena y absoluta libertad a las fuerzas del mercado; finalmente encontramos a quienes con mayor o mener radicalidad cuestionan al sisterna y pretenden su corrección o bien, en la medida que las correcciones sean incapaces de resolver los problemas, presentan como necesaria la búsqueda de una nueva forma de organización social.

Esta clasificación básica y primaria es importante tenerla en mente ya que la misma resulta úlil y necesaria a tin de explicar un segundo agrupamiento de las fuerzas sociales a partir de un segundo criterio, cual es: el origen o las raíces del conflicto actual. Asi tendriamos que para los representantes del primer agrupamiento el conflicto se explica por factores totalmente externos, para los segundos por lactores externos e internos y para los últimos por factores exclusivamente internos esencialmente.

Nos parece que son los dos criterios anteriores los que llevan a definir cual será la posición acerca de la búsqueda de posibles salidas al conflicto y particularmente, trente al debate nacional convocado por la Iglesia Católica.

Asl tendriamos que para quienes sostienen que los problemas económico-sociales se van a resolver dejando que actúe libremente la omnipoderosa y omnisapienle mano invisible de que hablaba Adam Smith, la 
única condición necesaria y suficiente sería neutralizar o eliminar los factores externos causantes del conflicto aclual, por tanto, el debate nacional no tendría ninguna razón de ser. Es precisamente el diagnóstico de la problemática y la solución a la misma la que conlleva a tal actilud, cuando se presupone de antemano que cualquier propuesta nacional frulo del debale mismo sería contraria a su posición.

A dilerencia de los exponentes de la primera posición, las restantes fuerzas sociales no sólo están dispuestas a particlpar en el debate sino que, aún más, lo conciben como algo necesario, consecuencia obvia de su diagnóstico de la realidad aclual y de las posibles soluciones a los problemas económico-sociales. Aunque no coincidan totalmente en sus concepciones, la segunda y tercera perspectiva dentro de las fuerzas sociales, si poseen los necesarios y suficientes puntos comunes respeclo a las raices de los problemas y sus posibles soluciones como para aceptar de buen grado el participar en el debale nacional promovido por la Iglesia.

Ahora bien, los tres agrupamientos de las fuerzas sociales quizas podrian calificarse, siguiendo el orden previamente establecido, como fuerzas conservadoras, reformistas y revolucionarias, tomando como base para ello el primer criterio agrupador. Ciertamente cada una de ellas no presenta una total homogeneidad encontrándose en su interior algunas organizaciones más o menos radicales en sus concepciones y a su vez tampoco creemos que la calificación pueda hacerse de una vez y para siempre, aunque su núcleo si lienda a permanecer siempre constante.

Hechas las anteriores aclaraciones que nos facilitan el trabajo exposilivo, nos parece fundamental expresar algunas interrogantes: en primer lugar, si las fuerzas conservadoras eslán seguras y convencidas de poseer razón en sus planteamientos ¿Por qué evitar el debale? ¿Será acaso que no confian en el poder de la razón? 0 , ¿Sencillamente dudando de su propia racionalidad hicieron un mal cálculo al suponer que sin su presencia tendrían la capacidad de fruslrar el evento?.

Ciertamente las razones expuestas directa 0 indireclamente por las fuerzas conservadoras no son muy convincentes y las acusaciones efectuadas a la Iglesia resultan lotalmente graluitas y antojadizas. Veamos algunos ejemplos:

La Cámara de Comercio e Industria "considera que dicho debate se convertirá en algo estéril, debido a que su real objetivo es juslificar el diálogo y la negociación como únicas formas para finalizar el confliclo".

"Las grandes mayorias de la población no destruyen ni se dividen radicalmente, son los grupos terrorislas y sus minorías de fachada quienes intentan hacerlo. ¿Es humano y racional negociar con esta gente?" 
Por otra parte "instituciones" como el Inslituto de Relaciones Internacionales (IRI) alirma que "EI llamado 'debate nacional' que está promoviendo el clero es parte de la conspiración del comunismo para tomar el poder en El Salvador...". "...el IRI reilera su advertencia al pueblo salvadoreno para que no participe ni apoye el 'debate nacional' del Arzobispado, debido a que ésle es una trampa de la estrategia conspirativa del FMLN-FDR".

O bien, el Instiluto Salvadoref́o de Estudios Polílicos, Económicos y Sociales (ISEPES), que pretende negar a la Iglesia su capacidad de promover el debate nacional al apelar al art. 82 de la Conslilución Política. Por otra parte afirma que "Rivera y Rosa Chávez estan haciendo una falsa represenlación de la Iglesia que ellos se han tomado".

Organizaciones como la Asociación Salvadorefia de Industriales se manifiestan en forma mucho más moderada: "... la Junta Directiva llegó a la conclusión de que el principio estatutario de apoliticidad impide a la gremial participar en lal actividad. Sin embargo, dijo que ASI está dispuesta a apoyar cualquier gestión encaminada a lograr la paz, incluyendo la de los curas, pero no a participar en ella".

A pesar de la oposición de las fuerzas conservadoras propagandizadas por un matulino ultra-conservador, la Conferencia Episcopal de $\mathrm{EI}$ Salvador (CEDES) expresó: "Los obispos de la Iglesia estamos renovando nuestro respaldo al Debate Nacional por la Paz... (y) ofrecen sus oraciones para que el debate logre el fin que se propone.

Lamentamos que se estén escuchando voces contrarias a esle Debate, propuesto por el Arzobispo de San Salvador, Mons. Arturo Rivera Damas, porque se trata de un esfuerzo amplio para que todas las fuerzas sociales, representalivas de la vida del país, busquen la paz que tanto necesitamos".

Como puede apreciarse, las fuerzas conservadoras se presentan opuestas al diálogo, a la búsqueda de un consenso como principio de solución a la crisis. Sus propias soluciones no parecen claramente explicitas en sus declaraciones, pero pueden reducirse al simplismo de sostener como la única solución al confliclo la derrola político-militar del FMLN; todo lo demás es considerado como confabulación del comunismo internacional, culpa de Nicaragua, Cuba y la URSS. No hay olra solución ya que la desestabilización interna, según su perspectiva, es el resultado de una agresión exlerna, solo la detención del "comunismo internacional" podría significar una real y verdadera solución. Su negativa de participar en el Debate Nacional, es en parte, resultado del análisis desde el cual parten y de los intereses que defienden.

Indudablemente que la no participación de eslas fuerzas en el Debate Nacional representa un vacío. Expresan una falta de visión política de la 
reproducción a largo plazo de sus intereses de clase. La cuestión ha sido ciclica y repetitiva.

Estas mismas fuerzas se opusieron a la implementación de una Reforma Agraria en el seminario convocado por la Fuerza Armada en 1970, lucharon tenazmenle conlra el tímido inlento de translormación agraria en 1976. Se opusieron y lucharon porque la proclama de la Fuerza Armada de 1979 quedara solamente en el papel. Ahora se oponen con tozudez a cualquier solución política del conflicto. Quizás estas fuerzas no sólo son conservadoras sino reaccionarias, en el senlido de su oposición activa a cualquier tipo de cambio.

El segundo y tercer bloque de fuerzas sociales han aceplado definilivamente el Debate Nacional como principio real de construcción de un consenso que supere a la actual crisis. Organizaciones laborales que en diferentes momenlos han apoyado la politica del Gobierno como la UPD y la UNOC participan dentro del Debate proporcionando sus propias ideas y perspectivas de análisis y solución. Lo mismo sucede con otras organizaciones que con mayor o menor grado de radicalidad han cuestionado al sistema.

Las más de 50 fuerzas sociaies que han mandado sus propuestas a la Iglesia Calólica son aquellas que realmenle buscan una solución política; son las que más han suirido las consecuencias del conflicto y por lo tanto propugnan por un término a la guerra.

La búsqueda de consenso, a través del examen de los punlos de coincidencia de estas organizaciones y el debate de sus diferencias dentro de un foro responsable, permitirá ir encontrando las bases de una solución que parle desde los intereses de las mayorias y sea consecuente con sus aspiraciones. Así como también lendrá por consecuencia el aislamiento de las minorías belicistas y relrógradas, opuestas a cualquier proyecto que de una u otra manera beneficie a las grandes mayorías populares. 